\title{
Noticias masoréticas en los midrašìm halákicos más antiguos y su comparación con los midrašìm exegéticos
}

\author{
Elvira MARTín CONTRERAS * \\ Instituto de Filología - CSIC, Madrid
}

El presente trabajo pone punto final al proyecto de investigación que he llevado a cabo en los dos últimos años ${ }^{1}$. El origen de dicho proyecto fue el análisis que realicé del midrás exegético Génesis $R a b b \hat{a}^{2}$, el cual reveló la existencia de más de ochenta interpretaciones basadas en detalles textuales. La comprobación de la información recogida en muchas de estas interpretaciones en listas y tratados masoréticos confirmó la información recogida en el midrás y, por lo tanto, su indiscutible valor textual. El gran número detectado, así como su estructura y formulación común, indicaban que era un práctica habitual de los rabinos, un recurso más de la interpretación midrásica.

De ahí surgió la idea de extender la identificación y el análisis de este tipo de comentarios a otros midrasî̀m. Elegí el otro midrás exe-

\footnotetext{
*emartin@filol.csic.es.

${ }^{1}$ Trabajo realizado gracias a una beca de perfeccionamiento de doctores en el extranjero financiada por el Ministerio de Ciencia y Tecnología.

${ }^{2}$ E. Martín CONTReras, La interpretación de la Creación. Técnicas exegéticas en el midrás Génesis Rabbâ (Estella 2002) cap. III, págs. 150-205.

Sefarad 63 (2003) págs. 119-139

(c) CSIC

ISSN 037-0894
} 
gético, Lamentaciones Rabbâ y los midrasî̀m halákicos más antiguos (Sifré Números, Sifra Levíticos y Mék̂îlta’de R. Yismael) para, además de conocer la incidencia y el uso de estos comentarios en cada midrás, poder comparar el tratamiento que reciben en los dos tipos de midrasî̀m.

Los resultados del análisis del midrás Lamentaciones Rabbâ, publicados en esta misma revista ${ }^{3}$, confirmaron la importancia de este tipo de interpretaciones dentro de la exégesis del midrás con un doble valor exegético-textual. Aunque en número menor (sólo diecinueve casos), la formulación y estructura siguen siendo comunes a todos los casos, y la mayoría de la información contenida en ellos es avalada por listas y tratados masoréticos.

En este artículo se ofrecen los resultados del análisis de los midrasî̀m halákicos más antiguos y su comparación con los resultados obtenidos en los midrasî̀m exegéticos. Al igual que en anteriores trabajos, todos los ejemplos que recogen y comentan un detalle textual son listados y estudiados. Dicho estudio consiste en la comprobación de las notas en las compilaciones masoréticas y en la descripción del método exegético que las explica.

El análisis del midrás Sifra Levíticos ha revelado que no contiene ningún comentario de este tipo. Por lo tanto, no aparece en la parte de estudio, pero sí es tenido en cuenta en la parte de comparación y conclusiones, pues la carencia de comentario es ya un resultado.

\section{MĔKÎILTA’ DE R. YISMAEL}

\subsection{Uso único}

El uso excepcional de una palabra o una expresión frente a su comportamiento generalizado se recoge en algunas notas masoré-

3 Cf. E. MARTín CONTRERAS, «Noticias masoréticas en el midrás Lamentaciones Rabbâ», Sefarad 62 (2002) págs. 125-141. 
ticas. Esta peculiaridad aparece interpretada en el midrás. Normalmente, la excepción frente a la norma general se marca mediante כולם 0 בכל.

Dos ejemplos en la Měkîllta' recogen e interpretan el uso excepcional de una expresión en un pasaje frente a su uso en toda la Biblia.

a) Be-šallah 5

En el versículo Ex 14,19 se emplea la expresión «ángel de Dios», מלאך האלהים , מלאך, frente a la más frecuente «ángel de $Y h w h »$,

Preguntó R. Natán a R. Simón ben Yohay: En todos los pasajes se dice: $Y$ el ángel de Yhwh la encontró (Gen 16,7), $Y$ el ángel de Yhwh le dijo (Gen 16,9), se le apareció el ángel de Yhwh (Ex 3,2), pero aquí se dice: Y se movió el ángel de Dios (Ex 14,19) ${ }^{4}$.

רבי שמעון בן יוחאי בכל מקום הוא אומר וימצאה מלאך "י ואמר לה מלאך

"י וירא מלאך "י אליו וכאן הוא אומר ויסע מלאך האלהים. 5

En la masora parva (MP) de la Biblia Hebraica Stuttgartensia ${ }^{6}$, se dice respecto a este compuesto: « 8 veces». La misma información se encuentra en una lista de Ginsburg donde se indican los ocho pasajes, entre los que se encuentra recogido el que aquí se comenta: Gen 31,11; Ex 14,19; Jue 6,20; Jue 13,6.9; 2Sam 14,17.20 y $19,28^{7}$.

4 Traducción española de T. MARTínez SÁIz, Mekilta de Rabbí Ismael (Navarra $1995)$ pág. 146.

5 Texto hebreo de J. Z. LauterbaCh, Mekilta de-Rabbi Ishmael. A Critical Edition on the Basis of the Manuscripts and Early Editions with an English Translation, Introduction and Notes, vol. I (Philadelphia 1949) pág. 226.

${ }^{6}$ Biblia Hebraica Stuttgartensia, ediderunt K. Elliger et W. RUdolPH, Textum Masoreticum curavit H. P. RUGER, Masoram elaboravit G. E. WEIL (Stuttgart 1977) pág. 109 [en adelante, $B H S$ ].

7 Cf. Ch. D. Ginsburg, The Masorah Compiled from Manuscripts, vol. II (Nueva York 1975) pág. 214, § 409. 
La información que aporta el midrás está confirmada por estas noticias, aunque éste sólo recoja uno de los ocho casos y, por lo tanto, la información sea parcial.

\section{b) Širata' 1}

En el presente ejemplo se comenta la ausencia en $2 \mathrm{Cr} 20,21$ de la expresión «porque es bueno», que suele formar parte de la fórmula de acción de gracias:

Y ¿en qué se diferencia esta acción de gracias de todas las otras acciones de gracias que hay en la Torá? En que en todas las acciones de gracias que hay en la Torá, se dice: Alabad a Yhwh porque es bueno, porque su clemencia es eterna (Sal 118,1), y aquí se dice: Alabad a Yhwh porque su clemencia es eterna $(2 \mathrm{Cr} 20,21)$, sólo porque, por así decirlo, no hubo alegría delante de Él en las alturas por la destrucción de los malvados ${ }^{8}$.

ומה נשתניה הודיה זו מכל ההודיות שבתורה שבכל הודיות שבתורה נאמר

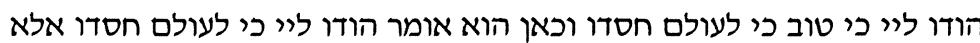

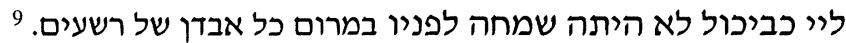

En $B H S$, en la MP a este pasaje ${ }^{10}$, encontramos la siguiente infor-

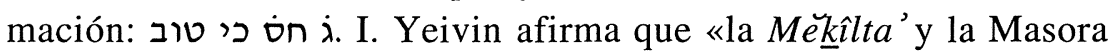
coinciden en señalar el mismo fenómeno. La única diferencia es que la Masora añade el número de casos» ${ }^{11}$.

\subsection{Kĕtîib}

Este término, cuando aparece de manera independiente, se utiliza para llamar la atención sobre una grafía determinada ${ }^{12}$. Además,

\footnotetext{
${ }^{8}$ Cf. T. MARTínez SÁlz, Mekilta, pág. 170.

${ }^{9}$ Cf. J. Z. LAUTERBACH, Mekilta de-Rabbi Ishmael, vol. II, pág. 5.

${ }^{10}$ Cf. Biblia Hebraica, pág. 1543.

${ }^{11}$ Cf. I. YEIVIN, Introduction to the Tiberian Masorah (Missoula 1980) pág. 133.

${ }^{12}$ M. H. HyVERnAT, «Le Langage de la Massora», Revue Biblique 13 (1904) págs. 521-546: págs. 543-544.
} 
puede ser empleado en un sentido más general, no en el técnico de la masora, para indicar que la grafía permite una vocalización diferente ${ }^{13}$.

Con esta última intención es utilizado en los dos ejemplos de la Mék̂ilta' en los que aparece, Be-šallah 7 y Širata' 8 . En ambos se señala el mismo fenómeno, la escritura defectiva de una palabra, que es la que se sigue en la interpretación y permite diferentes propuestas de lectura. En estos dos casos la propuesta es la misma: cambio de vocalización y lectura como otra palabra.

a) Be-šallah 7

La lectura del TM, le-susati, es cambiada en la interpretación a le-śaśti y samek y śin intercambiadas:

Le respondió R. Pappias: ¿Cómo interpretas: A mi yegua (l-ssty) [לסוסתי] ${ }^{14}$ entre los carros del faraón? (Cant 1,9). Le respondió R. Aqibah: Según está escrito: $l$-ssty [לססתי כתיב]. Dijo el Santo, bendito

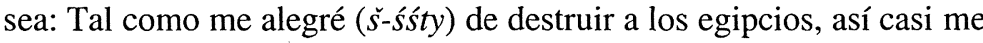
he alegrado (śśty) de destruir a Israel. Y ¿quién les hizo que se salvasen? A su derecha y a su izquierda $\left(\right.$ Ex 14,29) ${ }^{15}$.

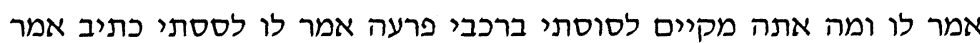

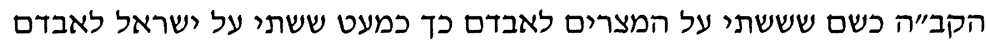
ומי גרם להם להנצל מימינם ומשמאלם שיתים ${ }^{16}$

En la MP de $B H S$ encontramos la siguiente noticia: ذ̇ חס ול בליש.

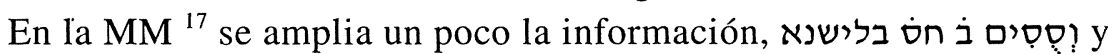
se enumeran los dos pasajes: $2 \mathrm{Sam} 15,1$ y el presente caso.

${ }^{13} \mathrm{Cf}$. W. BACHER, Die Exegetische Terminologie und Traditions exegetische Terminologie der Amoräer (Leipzig 1905) págs. 92-93; R. GoRDIS, The Biblical Text in the Making: A Study of the Kethib-Qere (s.1. 1971) pág. LII, nota 69.

14 TM: לִסְסָ.

${ }^{15}$ Cf. T. MARTínez SÁlz, Mekilta, págs. 160-161.

${ }^{16}$ Cf. J. Z. LAUTERBACH, Mekilta de-Rabbi Ishmael, vol. I, págs. 247-248.

${ }^{17}$ G. E. WeIL, Massorah Gedolah iuxta codicem Leningradensem B19a (Roma 1971) § 1786 
b) Širata' 8

La escritura defectiva del plural «dioses» en Ex 15,11 permite leerlo como «fuertes»:

Otra interpretación. ¿Quién como Tú entre los dioses [באלים], Yhwh? (Ex 15,11). Está escrito b'lym (es decir, 'fuerte') [באלם כתיב]. ¿Quién es como Tú entre los fuertes y quién como Tú en prodigios y proezas que hiciste junto al mar, porque se dice: de casos estupendos junto al Mar de los Juncos (Sal 106,22). Increpó al Mar de los Juncos y quedó $\operatorname{seco}(\text { Sal } 106,9)^{18}$.

דבר אחר מי כמוך באלים "י באלם כתיב מי כמוך באלמים ומי כמוך בנסים

וגבורות שעשית על הים שנאמר נוראות על ים סוף וגו' ויגער בים סוף ויחרב.

No he encontrado ninguna lista que confirme esta información, aunque en la MP a este pasaje se dice $\dot{j}$.

\subsection{Palabras sin construcción gramatical definida}

Las cinco expresiones de la Biblia cuya secuencia gramatical no está clara son señaladas y su inconsistencia explicada en Amaleq 1:

Issi ben Yehudah dice: Estas son las cinco palabras cuya construcción gramatical no está decidida: śt ' '¿no lo levantarías?' 'rwr: 'maldito'. $m h r$ : 'mañana'. mšqdym: 'en forma de almendras'. w-qm: 'y se levantará'. śt t: porque se dice: Si obras bien, ¿no lo levantarías? (Gn 4,7), o quizá: «lo levantarías, aunque no obrases bien». 'rwr: maldita su cólera, porque es fuerte (Gn 49,7), o: porque en su cólera mataron a un hombre y en su pasión desjarretaron un toro maldito (Gn 49,6-7).

(De igual manera el pasaje donde se dice:) Mañana yo estaré sobre la cima de la colina (Ex 17,8) (podría también ser leído:) Sal a luchar contra Amaleq mañana.

${ }^{18}$ Cf. T. MARTínez SÁIz, Mekilta, pág. 201.

${ }^{19}$ Cf. J. Z. Lauterbach, Mekilta de-Rabbi Ishmael, vol. II, pág. 60. 
(De igual manera el pasaje donde se dice:) en forma de flores de almendro con sus botones y sus flores (Ex 25,34), (podría también ser leído): $Y$ en el candelabro, cuatro cálices en forma de flores de almendro.

(El pasaje donde se lee:) Y se levantará este pueblo y se prostituirá (Dt 31,16), (podría leerse): He aquí que tú vas a acostarte con tus padres y este pueblo se levantará. Éstas son las cinco expresiones cuya construcción gramatical no está decidida ${ }^{20}$.

איסי בן יהדה אומר אלו חמשה דברים בתורה שאין להם הכרע שאת. ארור.

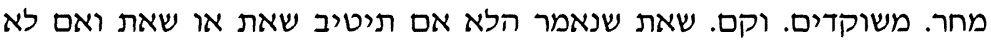

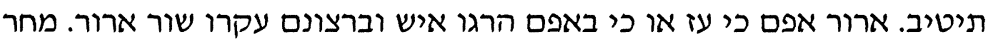

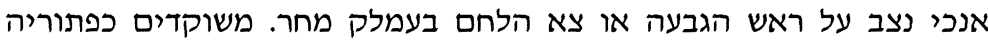

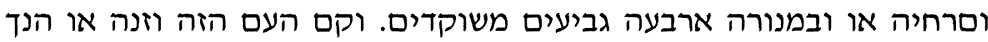
שוכב עם אבותיך וקם אלו חמשה דברים שבתורה שאין להם הכרע.

Una lista del sefer 'Okla $\hat{a}^{22}$ ofrece las cinco palabras y sus versículos, pero en ella no se expone de forma detallada la doble posibilidad de cada una de las palabras, como ocurre en el midrás.

\subsection{Correcciones para el rey Tolomeo ${ }^{23}$}

La tradición de los pasajes que los sabios cambiaron para el rey Tolomeo en la Septuaginta es ampliamente recogida en la literatura rabínica ${ }^{24}$.

${ }^{20}$ Cf. T. MARTínez SÁIZ, Mekilta, pág. 249.

${ }^{21}$ Cf. J. Z. LAUTERBACH, Mekilta de-Rabbi Ishmael, vol. II, págs. 142-143.

${ }^{22}$ S. FrenSDORFF, Ochlah W'ochlah (Hannover 1864) § 194, pág. 121.

${ }^{23}$ Cf. E. Tov, «The Rabbinic Tradition Concerning the 'Alterations' Inserted into the Greek Pentateuch and their Relation to the Original Text of the LXX», JSJ 15 (1984) págs. 65-89; C. MCCARTHY, The Tiqqune Sopherim and Other Theological Corrections in the Masoretic Text of the Old Testament (Gotinga 1984) págs. 131-137.

${ }^{24}$ Las principales fuentes son: Mĕgil $\cdot l a \hat{a} 9 \mathrm{a} ; \mathrm{j} M$ ĕgill lâ $71 \mathrm{~d} ;$ ARNb 37,1; Tanhûma' Ex 4,20; Měkîlta' sobre Ex 12,40. 
El número de cambios efectuados difiere según la fuente consultada. En las listas presentes en el Tanhûma ${ }^{25}$ y en el $A R N^{26}$ se señalan al principio diez casos, aunque a continuación se enumeren catorce y once casos respectivamente. En jMĕgil-lâ 71d se indica el número de trece ${ }^{27}$. En Mégil lâ 9 a no se enuncia ningún número y se ofrecen quince cambios ${ }^{28}$. En Éxodo Rabbâ 5,5, sobre Ex 4,20, se señala el número de dieciocho, pero no se enumeran.

En la Měk̂ilta', Pisha' 14, no se indica número, pero se ofrecen los mismos trece casos que en jMĕgil llâ $71 \mathrm{~d}$ :

El tiempo que los hijos de Israel moraron en Egipto y en el país de Canaán y en la tierra de Gosen fueron cuatrocientos treinta años (Ex 12,40). Este es uno de los pasajes que escribieron para el rey Tolomeo.

Análogamente le escribieron: Dios creó en el principio (Gn 1,1); Haré a un hombre de acuerdo con una imagen y una semejanza (Gn 1,26); macho con sus correspondientes orificios lo creó (Gn 5,2); y acabó en el día sexto... y descansó en el día séptimo (Gn 2,2); Ea, voy a bajar y confundiré allí su lengua (Gn 11,7); $Y$ se rió Sara entre sus parientes $(\mathrm{Gn} 18,12)$; porque en su cólera mataron un toro y en su resolución desjarretaron un cebón (Gn 49,6); Y Moisés tomó a su mujer y a sus hijos y los hizo cabalgar sobre un portador de hombres (Ex 4,20); No he tomado de ellos nada deseable (Nm 16,15); Que Yhwh, tu Dios, les ha adjudicado para iluminar a todos los pueblos (Dt 4,19); Que mandé a las naciones no darles culto (Dt 17,3); Y a la de pies pequeños (Lv 11,6). Y también le escribieron: El tiempo que los hijos de Israel moraron en Egipto y en el país de Canaán y en la tierra de Gosen fueron cuatrocientos treinta años ${ }^{29}$.

${ }^{25} \mathrm{Gn} 1,1.26 .27 / 5,2 ; 2,2 ; 11,7 ; 18,12 ; 49,6 ;$ Ex 4,$20 ; 12,40 ; 24,5.11 ; \mathrm{Lv} 11,6 ; \mathrm{Dt}$ 4,$19 ; 17,3$

${ }^{26}$ Gn $1,1.26 .27 / 5,2 ; 11,7 ; 18,12 ; 49,6$; Ex 4,20;12,40; Nm 16,15; Lv 11,6; Dt 4,19 .

${ }^{27}$ Ex 4,20; Gn 1,1.26.27/5,2; 2,2; 11,7; 18,12; 49,6; Ex 12,40; Nm 16,15; Dt 4,$19 ; 17,3 ; \operatorname{Lv} 11,6$.

${ }^{28}$ Gn $1,1.26 .27 / 5,2 ; 2,2 ; 11,7 ; 18,12 ; 49,6 ;$ Ex 4,$20 ; 12,40 ; 24,5.11 ; \operatorname{Lv} 11,6$; Nm 16,15; Dt 4,19; 17,3.

${ }^{29}$ Cf. T. MARTínez SÁIz, Mekilta, pág. 74. 
ומושב בני ישראל אשר ישבו במצרים ובארץ כנען ובארץ גושן שלשים שנה

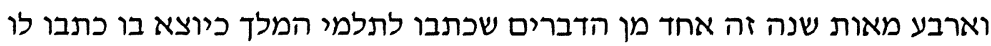

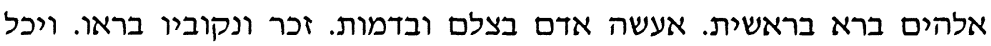

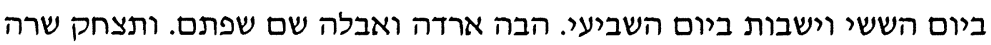

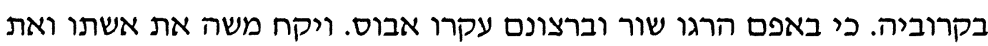

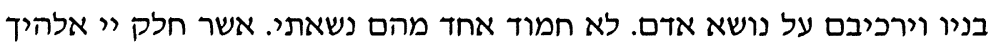

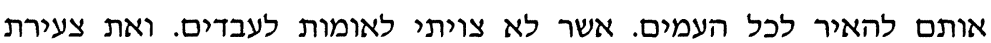

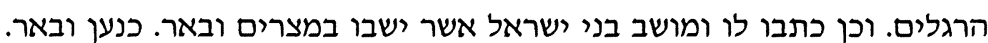

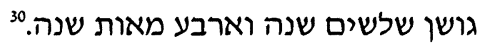

\subsection{Tiqqûnê sôferîm}

Literalmente 'correciones de escribas', es el nombre con el que se designa a los dieciocho pasajes que, según la tradición judía, han sido alterados en el texto bíblico. Según la explicación más común, se refieren a los cambios hechos por motivos teológicos ${ }^{31}$.

Listas de estos cambios se encuentran en la masora y las fuentes talmúdicas, aunque presentan diferencias en el número. En $S N m$ sobre Nm 10,35, se recogen ocho casos ${ }^{32}$, y en el Tanhûma' dieci-

${ }^{30}$ Cf. J. Z. LAUTERBACH, Mekilta de-Rabbi Ishmael, vol. I, págs. 111-112.

${ }^{31} \mathrm{Cf}$. CH. D. GinsBurg, Introduction to the Massoretico-Critical Edition of the Hebrew Bible (Nueva York 1996) pág. 347; también S. Lieberman, Hellenism in Jewish Palestine (Nueva York 1950) págs. 28-37, defiende la tradición, aunque desde el estudio de la complejidad de este fenómeno. La postura extrema es defendida por E. W. Barnes quien mantiene que estas correcciones pertenecen más a la tradición del midrás y que son interpretaciones y no lecturas: cf. E. W. BARNES, «Ancient Corrections in the Text of the Old Testament (Tikkun Sopherim)», JTS 1 (1900), reimpreso en S. Z. LEIMAN (ed.), The Canon and Masorah of the Hebrew Bibles: The Talmudic and Midrashic Evidence (Nueva York 1974). Y, por último, los autores que consideran necesaria una postura crítica para investigar estas correcciones: cf. D. BARTHÉLEMY, «Les Tiqquné Sopherim et la critique textuelle de l'Ancien Testament», SVT 9 (1962) págs. 285-304; C. MCCARTHY, The Tiqqune Sopherim, págs. 17-24, sobre el estado de la cuestión y su amplio estudio de esta compleja tradición.

${ }^{32} \mathrm{Nm} \mathrm{11,15;} \mathrm{12,12;} \mathrm{Jer} \mathrm{2,11;} \mathrm{Ez} \mathrm{8,17;} \mathrm{Hab} \mathrm{1,12;} \mathrm{Zac} \mathrm{2,12;} \mathrm{Sal} \mathrm{106,20;} \mathrm{Job} \mathrm{7,20.}$ Véase parágrafo 2.2 . 
siete casos ${ }^{33}$. Esta última versión es la que siguieron las listas masoréticas que presentan el número definitivo de dieciocho, contando como dos los cambios de $\mathrm{Nm} \mathrm{12,12}{ }^{34}$.

En la Měkîlta', en Širata' 6 , se ofrece una lista con once casos ${ }^{35}$ :

Ciertamente quien os toca, toca la niña de sus ojos (Zc 2,12). R. Yehudah dice: No se dice aquí «la niña de los ojos», sino «la niña de sus ojos», refiriéndose, por así decirlo, al Altísimo; pero la Escritura modificó la expresión.

Análogamente se dice: $Y$ exclamáis: ¡qué fatiga! y lo desdeñáis, etc. (Ml 1,13); pero la Escritura modificó la expresión. Análogamente se dice: Por el crimen de que, sabiendo que sus hijos le maldecían etc. (1Sm 3,13); pero la Escritura modificó la expresión.

Análogamente se dice: ¿Por qué me has puesto por blanco tuyo y he venido a ser para ti una carga? (Jb 7,20); la Escritura modificó la expresión. Análogamente se dice: ¿No eres Tú desde antiguo, oh Yhwh, mi Dios, mi Santo? No moriremos (Hb 1,12). La Escritura modificó la expresión.

Análogamente se dice: ¿Acaso nación alguna cambió de dioses, aunque ellos no sean dioses? Pues mi pueblo ha cambiado su gloria (Jr 2,11). La Escritura modificó la expresión. Análogamente se dice: Pues ellos cambiaron su gloria por la imagen de un buey que come hierba (Sal 106,20). La Escritura modificó la expresión.

Análogamente: Si así has de tratarme... y que no vea yo mi desventura (Nm 11,15). La Escritura modificó la expresión. Análogamente: No tenemos parte alguna con David... ;cada uno a sus tiendas, Israel! (2Sm 20,1). La Escritura modificó la expresión.

${ }^{33}$ Gn 18,22; Nm 11,15; 12,12; 1 Sam 3,13; 2 Sam 16,12; 20,1; 1 Re 12,6; Jer 2,11; Ez 8,17; Os 4,7; Hab 1,12; Zac 2,12; Mal 1,13; Sal 106,20; Job 7,20; 32,3; Lam 3,$20 ; 2$ Cr 10,16 .

${ }^{34}$ Cf. CH. D. Ginsburg, The Masorah, vol. II, pág. 214, § 409; Cf. S. FrensdorfF, Ochlah W'ochlah, pág. $113, \S 168$; S. BAER y H. L. STRACK, Diqduqe hatte'amim (Jerusalem 1970) págs. 44-45, §57.

${ }^{35} \mathrm{Nm} \mathrm{11,15;12,12;1}$ Sam 3,13; 2 Sam 20,1; Jer 2,11; Ez 8,17; Hab 1,12; Zac 2,12; Mal 1,13; Sal 106,20; Job 7,20. 
Análogamente: Pues he aquí que se llevan el ramo a la nariz (Ez 8,17). La Escritura modificó la expresión. Análogamente: Cuando sale del vientre de su madre (Nm 12,12): tendría que haber dicho «del vientre de nuestra madre» pero la Escritura modificó la expresión ${ }^{36}$.

וכן הו אומר כי הנוגע בכם נוגע בבבת עינו רבי יהודה בבבת עין אינ אינו אומר

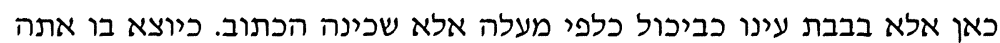

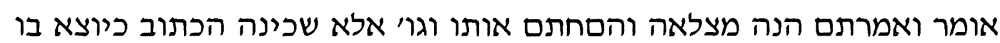

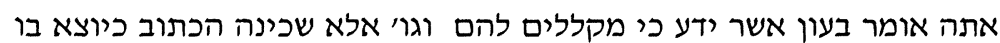

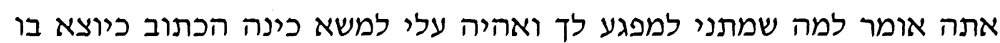

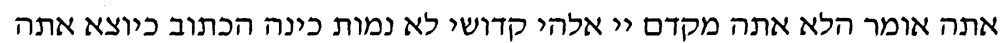

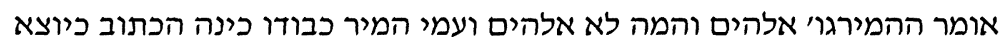

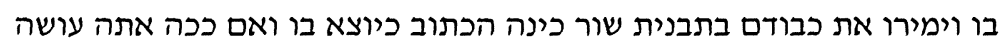

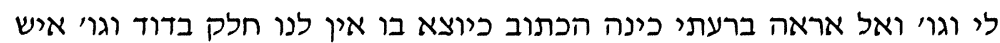

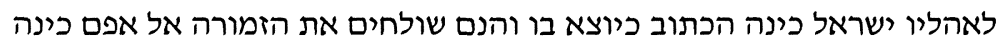

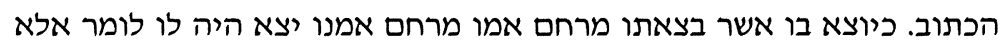

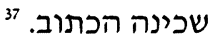

Y otra vez se repite el versículo inicial y la opinión de R. Yehudah.

Hay que destacar que la forma de indicar el primer versículo que se recoge en esta lista como corregido, Zac 2,12, es mediante el

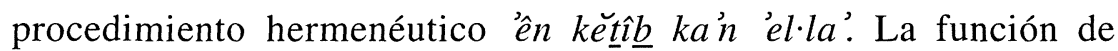
dicho procedimiento consiste en marcar lo que está escrito en la Biblia, en oposición a otras posibles formas de expresarse, más comunes, pero que no son las que presenta el texto bíblico ${ }^{38}$. Podría entonces ser contradictorio su uso en este caso en el que se indica explícitamente una modificación del texto bíblico. Pero creo que, lejos de ser una contradicción, el uso de este recurso refuerza la explicación teológica que se da a este cambio y justifica la manipulación del texto sagrado.

${ }^{36}$ Cf. T. MARTínez SÁIZ, Mekilta, pág. 191.

${ }^{37}$ Cf. J. Z. LAUTERBACH, Mekilta de-Rabbi Ishmael, vol. II, págs. 43-45.

${ }^{38}$ Cf. E. Martín Contreras, «En... 'el·la'en la exégesis de Génesis Rabbâ», en Exégesis Rabínica: Lengua y Literatura (= Ilu 3), ed. Luis F. Girón BLANC (Madrid 2000) págs. 147-157. 


\section{SIFRÉ NÚMEROS (SNM)}

\subsection{Puncta extraordinaria}

En la Biblia existen quince palabras marcadas con puntos sobre una o más letras de una palabra, diez en la Torá y las otras cinco en los Profetas y en los Escritos ${ }^{39}$.

En el Midrás, SNm y 'A $\underline{b} \hat{t} \underline{t}$ de Rabbi Natán $(A R N)$, sólo se mencionan las diez veces que aparecen en la Torá; el único caso localizado en los Escritos, Sal 27,13, se señala en Bĕrak $\underline{o} \underline{t}$ 4a; y de los otros cuatro casos de Profetas no existe ninguna referencia en el Talmud.

La intención original de estos puntos es difícil de precisar. En la literatura midrásica se encuentran dos explicaciones diferentes a este fenómeno: 1) como marca de palabras dudosas ${ }^{40}$;2) artificio puramente exegético ${ }^{41}$. También los autores modernos han intentado darles una explicación, sin resultados satisfactorios hasta el momento ${ }^{42}$.

En SNm, en la parašâ Beháaloteka sobre Num 9,10, se da la lista con los diez versículos que contienen palabras puntuadas, en algunos casos se dice sobre qué palabra o letra va el punto, y se ofrece la explicación exegética de cada caso ${ }^{43}$ :

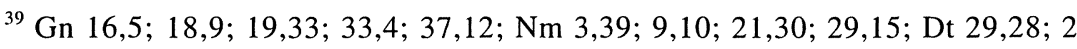
Sam 19,20; Is 44,9; Ez 41,20; 46,22; Sal 27,13.

${ }^{40}$ ARNa 34,5, B 37,6 y Números Rabbâ 3,13.

${ }^{41}$ Génesis Rabbâ 48,15 y 78,9.

${ }^{42}$ Cf. I. HARRIS, «The Rise and Developtment of the Massorah. I», JQR 1 (18981899 ) págs. 128-142: pág. 134; G. E. WEIL, Initiation à la Massorah (Leiden 1964) págs. 30-31; CH. D. GinsBURG, Introduction, pág. 334; I. YeIVIN, Introduction, págs. 44-46.

${ }^{43}$ Para un estudio detallado de esta lista, cf. $\mathrm{CH}$. D. GinsBURG, Introduction, págs. 318-331.
} 
O se halle en tierra lejana $(\mathrm{Nm} 9,10)$. El punto sobre lejana quiere decir que nadie que esté impuro, aunque esté cerca, puede celebrar la pascua con ellos.

De modo similar: Juzgue Yhwh entre tú y yo (Gn 16,5); el punto arriba significa que ella le hablaba sólo del tema de Hagar, aunque hay quienes dicen que se refería a los que fomentaban la querella entre él y ella. Igualmente: [Los angeles] le dijeron: ¿dónde está Sara tu mujer? (Gn 18,9); el punto arriba significa que sí sabían dónde estaba. Del mismo modo: El Lot no se dio cuenta de cuándo ella se acostó y se levantó (Gn 18,33); el punto sobre ella se acostó quiere decir que no advirtió cuándo ella se acostó, pero sí cuándo se levantó. De forma análoga: Y le besó [Esaú a Jacob] (Gn 33,4); el punto arriba significa que no se besaron de corazón; pero R. Simón ben Yojay explicaba: Es tradición segura que Esaú odiaba a Jacob, pero ocurrió que en aquel momento se conmovieron sus entrañas y se besaron de todo corazón. Igualmente: Fueron sus hermanos a pastorear el rebaño de su padre en Sikem (Gn 37,12); el punto arriba significa que no fueron sino a apacentarse a sí mismos. De modo similar: Total de los empadronados entre los levitas, los que empadronaron Moisés y Aarón (Nm 3,39); el punto arriba significa que Aarón no se incluía en el cómputo. De modo similar: Hemos devastado hasta Nofa, que está junto a Maydeba $(\mathrm{Nm}$ 21,30); el punto arriba significa que también más allá fue así. De modo similar: [Y ofreceréis] décimo a décimo $(\mathrm{Nm} 29,15)$; el punto sobre décimo significa que no había más que un décimo. De modo similar: Las cosas secretas corresponden a Yhwh nuestro Dios; mas las reveladas, a nosotros y a nuestros hijos por siempre (Dt 29,28); el punto arriba significa que [Dios] les dijo: «Puesto que habéis puesto en práctica las revelaciones, también yo os daré a conocer los secretos» ${ }^{44}$.

או בדרך רחוקה נקוד על הה"א אפילו בדרך קרובה והוא טמא לא היה היה עושיה

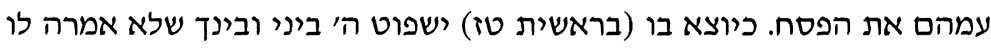

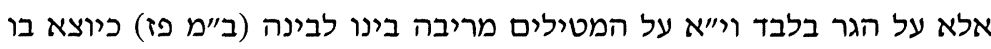

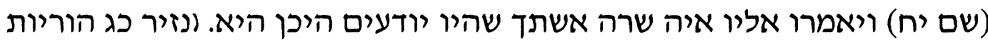

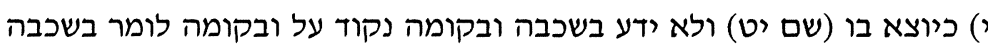

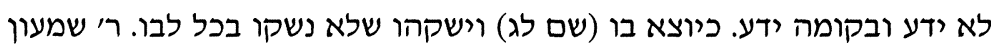

${ }^{44}$ Traducción española de M. PÉREz FERnÁNDEZ, Midrás Sifre Números (Valencia 1989) pág. 197. 


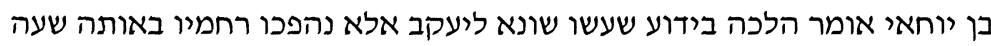

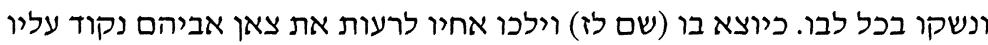

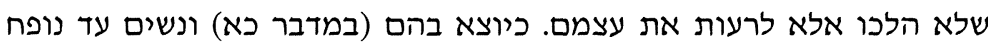

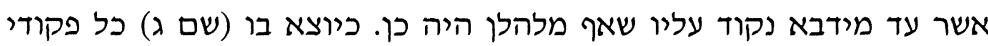

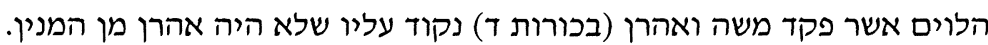

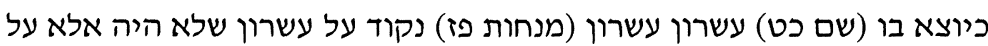

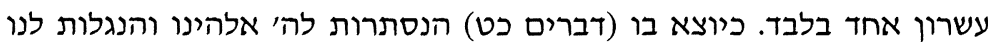

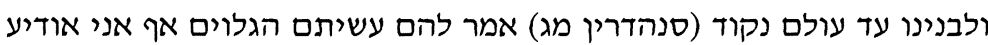

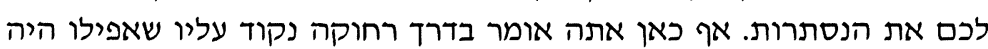
בדרך קרובה והיה טמא לא היה עושה עמהם את את הפסח.

La lista concluye con la repetición del primer párrafo. La interpretación ofrecida en ella coincide con la que se recoge en las listas masoréticas ${ }^{45}$, y es la que han seguido los estudiosos modernos para establecer la función de estos puntos.

\subsection{Nûn invertido}

Este signo aparece marcado en la Biblia en nueve ocasiones, de las cuales siete se encuentran en el libro de Números $^{46}$. Recibe también el nombre de nûn hafûkâ y nûn menuzeret, y asume varias formas. La más habitual es mediante un símbolo parecido a nuestros actuales corchetes, [, aunque en algunas tradiciones se describe como $\supset$ y en las fuentes griegas como una sigma invertida.

En $\mathrm{SNm}$ sobre Nm 10,35 se indica la existencia de este signo en este versículo y se dan dos explicaciones de su función:

Cuando el arca partía (Nm 10,35). Hay un punto arriba y otro abajo, porque [el versículo] no está en su sitio. Rabbi interpretaba: Eso es porque [el versículo] constituye un libro por sí mismo. De aquí han

\footnotetext{
${ }^{45}$ Cf. Ch. D. GinsBurg, The Masorah, vol. III, pág. 38, § 14, págs. 364-365, § 39. S. FRENSDORFF, Ochlah W'ochlah, § 96.

${ }^{46} \mathrm{Nm}$ 10,35-36; Sal 107,23-28.40; cf. CH. D. GinsBurg, The Masorah, vol. II pág. 259, § 15; S. FRENSDORFF, Ochlah W'ochlah, § 179.
} 
dejado dicho: Cuando un libro se borra, si le quedan ochenta y cinco letras como en la perícopa «cuando el arca partía», vuelve las manos impuras.

R. Simón explicaba: Hay un punto arriba y otro abajo [de los versículos 35 y 36 de Num 10] porque este no es su sitio. ¿Qué se debía haber escrito en su lugar? Sucedió que el pueblo comenzó a lamentarse malamente $(\mathrm{Nm} \mathrm{11,1})^{47}$.

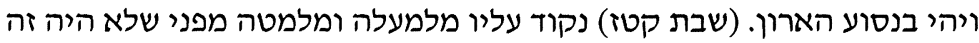

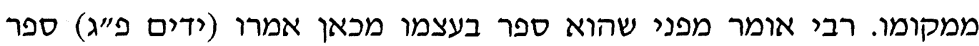

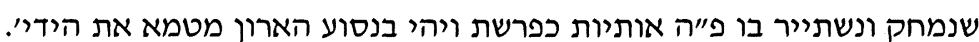

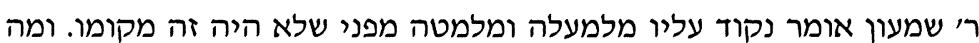

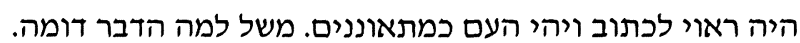

Según estas opiniones, la función del nûn invertido es similar a la de los signos empleados por los críticos griegos para indicar que se debía introducir un espacio entre dos pasajes, o para marcar pasajes incluidos en un lugar erróneo ${ }^{48}$.

\subsection{Tiqqûnê sôferîm ${ }^{49}$}

En la parasầ Beháaloteka sobre Num 10,35, se encuentra una lista con ocho cambios ${ }^{50}$ :

Quien os toca, toca la niña de su ojo (Zac 2,12). R. Yehudah interpretaba: No se dice «la niña del ojo», sino «la niña de su ojo». Si así puede decirse, esta Escritura se refiere a lo Alto, sólo que ha hecho una modificación en el texto.

\footnotetext{
${ }^{47}$ M. PÉrez Fernández, Midrás Sifre, págs. 227-228.

${ }^{48}$ Cf. S. Lieberman, Hellenism, págs. 38-43.

${ }^{49}$ Véase 1.5 sobre explicación del fenómeno.

${ }^{50}$ Para un análisis detallado de esta lista, cf. C. MCCARThy, The Tiqqune Sopherim, págs. 25-30.
} 
Del mismo modo: ¿Por qué me has puesto por blanco tuyo y he venido a ser para ti una carga? (Jb 7,20): ¡solo que ha hecho una modificación en el texto!; del mismo modo: Y llevan el ramo a su nariz (Ez 8,17): ¡solo que ha hecho una modificación en el texto!; del mismo modo: ¿No eres Tú desde antiguo, oh Yhwh, mi Dios, mi Santo? No moriremos $(\mathrm{Hb} 1,12)$; ¡solo que ha hecho una modificación en el texto!; del mismo modo: cambiaron la gloria de ellos por la imagen de un toro que come heno (Sal 106,20): ¡solo que ha hecho una modificación en el texto!; del mismo modo: Si así has de tratarme mátame del todo, por favor, si he hallado gracia a tus ojos, para que de este modo no vea ya mi desventura ( $\mathrm{Nm} \mathrm{11,15):} \mathrm{¡solo} \mathrm{que} \mathrm{ha} \mathrm{hecho} \mathrm{una} \mathrm{modificación} \mathrm{en} \mathrm{el}$ texto!; del mismo modo: Pues mi pueblo ha cambiado su gloria ( $\mathrm{Jr}$ 2,11): ¡solo que ha hecho una modificación en el texto!; del mismo modo: Te ruego que no sea ella como el nacido muerto, quien al salir del vientre de su madre tiene ya consumida la mitad de su carne $(\mathrm{Nm}$ 12,12): ¡solo que ha hecho una modificación en el texto! ${ }^{51}$.

וכן הוא אומר (זכריה ב) כל הנוגע בהם כנוגע בבבת עינו בבת עין לא נאמר

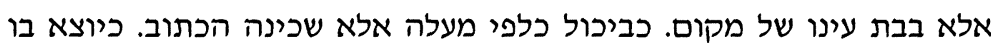

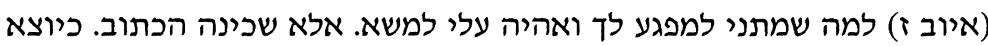

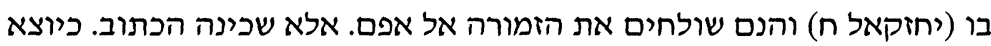

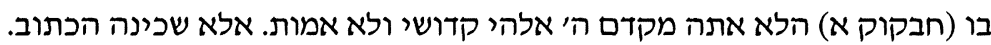

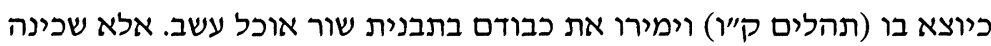

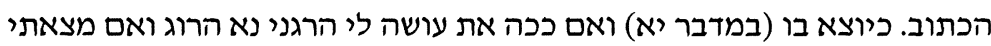

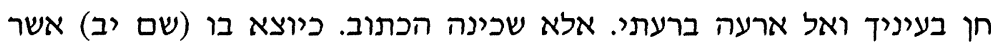

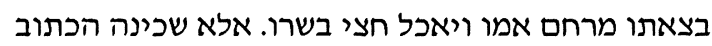

Al igual que ocurría con la lista ofrecida en la Mẹk $\underline{\imath} l t a$, , el primer versículo es introducido mediante el recurso hermenéutico ền kétît $\underline{b}$ ka'n 'el.la' (vid. supra).

Más adelante, en la parašâ Huqqat sobre Num 19,17 , se señala un cambio más con esta terminología, pero no está registrado en el TM ni en ninguna lista masorética:

${ }^{51}$ M. PÉrez FernándeZ, Midrás Sifre, págs. 230-231. 
Para el impuro se tomará polvo de la hoguera del sacrificio por el pecado (Num 19,17). ¿Es que es polvo? ¿Acaso no es ceniza? ¿Por qué razón la Escritura hace una modificación del texto? Porque pretende una comparación con otra $\operatorname{cosa}^{52}$.

ולקחו לטמא מעפר שריפת החטאת (סוטה טז) וכי עפר הוא והלא אפר

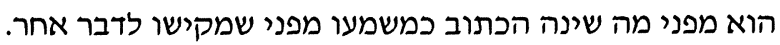

En este caso, el procedimiento seguido se asemeja más al recurso exegético 'al tiqrê, cuya función consiste en introducir otra interpretación basada en el cambio de la vocalización o del texto consonántico, pero sin anular o suplantar al texto oficial ${ }^{53}$. La «modificación» propuesta consiste en cambiar $\mathcal{N}$ por y así interpretar con una argumentación por heqqes.

\section{COMPARACIÓN Y CONCLUSIONES ${ }^{54}$}

Una vez analizados todos los midrasîm, tanto halákicos como exegéticos, e identificados todos los comentarios textuales presentes en ellos, es posible comparar ambos tipos. El siguiente cuadro-resumen constituye un buen punto de partida para la comparación, pues permite ver el tipo de noticas que se recogen en estos midrasî̀m, su incidencia por midrás y también en conjunto:

${ }^{52}$ M. PÉrez FernándeZ, Midrás Sifre, pág. 406.

${ }^{53}$ Cf. A. ARZI, «Al Tikrei», EJ (Jerusalem 1971) vol. II, col. 776. Cf. C. MCCARTHY, The Tiqqune Sopherim, págs. 162-166, sobre comparación de los dos fenómenos.

${ }^{54}$ Algunas de las conclusiones aquí expuestas fueron presentadas en el seno de los Seminarios de Filología e Historia del CSIC, y un resumen fue publicado en E. MARTÍN CONTRERAS, «El midrás hagádico: Interpretación y Transmisión Textual», Memoria de los Seminarios de Filología e Historia. CSIC, eds. C. López Ruiz y S. TORALLAS TOVAR (Madrid 2002) págs. 63-67: págs. 66-67. 


\begin{tabular}{|c|c|c|c|c|c|}
\hline & GenR & LamR & Měkîlta' & $\begin{array}{c}\text { Sifra } \\
\text { Levíticos }\end{array}$ & $S N m$ \\
\hline Nûn invertido & 1 & - & - & - & 1 \\
\hline Puncta extraordinaria & 5 & - & - & - & lista $(10)$ \\
\hline Tiqqûnê sôferîm & 1 & - & lista (11) & - & lista (8) \\
\hline Qerêe-kĕtît $\underline{b}$ & 1 & - & - & - & - \\
\hline $\begin{array}{l}\text { Cambios para el rey Tolo- } \\
\text { meo }\end{array}$ & 5 & - & lista (13) & - & - \\
\hline$K \breve{e} \underline{t} \underline{\imath} \underline{b}$ & 49 & 15 & 2 & - & - \\
\hline male' y haser & 5 & 1 & - & - & - \\
\hline Computación numérica & 16 & 2 & - & - & - \\
\hline Uso único & 1 & - & 2 & - & - \\
\hline Sebirîm & - & 1 & - & - & - \\
\hline $\begin{array}{l}10 \text { qal wa-homerîm en la } \\
\text { Biblia }\end{array}$ & 9 & - & - & - & - \\
\hline $\begin{array}{l}\text { Palabras con construcción } \\
\text { gramatical no definida }\end{array}$ & lista (5) & - & lista (5) & - & - \\
\hline TOTAL & 98 & 19 & 7 & 0 & 3 \\
\hline
\end{tabular}

Como se desprende de estos resultados, este tipo de comentarios textuales es más numeroso en los midrasî̀m exegéticos, con una incidencia sin igual en GenR, especialmente los introducidos con el término kétî́b. Pero no sólo en cantidad destacan los midrasîm exegéticos, sino también en variedad. Frente a los midrasî̀m halákicos, en los que sólo se ofrecen las listas de las correcciones más representativas realizadas por los sôferîm y por lo tanto muy conocidas, los midrasî̀m exegéticos señalan y comentan diversos fenómenos textuales de muy distinta naturaleza. Junto a los casos de cambios hechos por los sôferîm, se ofrecen otro tipo de peculiaridades textuales, como la escritura plena o defectiva de una palabra, las veces que aparece una palabra o una expresión en la Biblia, sin contar la variedad de fenómenos indicados mediante el término kět tîb $\underline{b}$. 
En cuanto a las noticias que ambos tipos tienen en común, la comparación permite apreciar algunas diferencias respecto al tratamiento y la fórmula:

- En el caso de los tiqqûnê sôferîm y de los cambios realizados para el rey Tolomeo, en la Měk̂́lta' y en SNm se aportan listas con el número total de los casos y con los ejemplos que los ilustran; esto contrasta con el tratamiento dado a estos fenómenos en GenR, donde sólo se recogen cuando en el comentario se interpretan los versículos afectados por dichas marcas, por lo que el número indicado es menor.

Además, en el caso de los tiqqûnê sôferîm, existe entre ambos tipos de midrasìm una diferencia en la terminología: en la Měkîlta' y en $S N m$ estos cambios son denominados kinnuyim, 'eufemismos', y en GenR, tiqqûn, 'corrección' 55 . Pese a la disparidad de número entre la lista de la Měk̂́lta' (once casos) y la de $S N m$ (ocho casos), ambas representan la misma tradición, separada de la recogida en GenR.

- El fenómeno de los puncta extraordinaria en $S N m$ recibe un tratamiento diverso al que se le da en GenR. En el primero se ofrece una lista con los diez casos presentes en la Torá y su interpretación, pero en GenR, al igual que ocurría en los fenómenos mencionados más arriba, no se aporta ninguna lista. Sólo cinco casos son señalados cuando en el comentario se interpretan los versículos que los contienen.

En GenR se ofrece una explicación novedosa de este fenómeno. Una nueva regla de interpretación es enunciada y seguida en los cinco casos que se recogen en el midrás. Según esta regla y su aplicación, se puede afirmar que en este midrás los puntos tienen una función exegética y que, por lo tanto, no son considerados marcas de crítica textual para indicar que las letras deben ser borradas,

${ }^{55}$ Cf. C. MCCARTHY, The Tiqqune Sopherim, págs. 167-196. 
sino un recurso más del comentario midrásico. Así, la explicación de tres de los casos localizados en GenR es distinta de la que se presenta en $S N m$. En los otros dos casos, tanto en GenR como en $S N m$ se ofrece la misma conclusión exegética, sin que eso sea incompatible con la regla enunciada en GenR, fielmente seguida en esos dos casos.

En mi opinión, en los casos en los que la explicación presentada en GenR difiere de la de $S N m$, aquella es más satisfactoria que la aportada en el SNm.

- La lista de palabras cuya construcción gramatical no está definida, que se recoge en la $M e$ ěkilta , está más desarrollada que la aportada en GenR. Mientras que en la lista de este último sólo se indican las palabras afectadas por este problema y su localización; en la de la Měk̂llta' se ofrecen además las dos posibilidades de lectura de cada una de las cinco palabras, explicación original de este midrás.

En conclusión, el hecho de que en los midrasîm exegéticos no se aporten listas, sino que cada vez que se comenta un versículo afectado por una de estas marcas se señale y comente dicho fenómeno; el que el procedimiento y la formulación sean comunes; y el que la presencia de estos comentarios sea más numerosa, demuestra que era una práctica habitual dentro de la interpretación de este tipo de midrasîm. No así en los halákicos, donde dichos comentarios parecen ser aislados; en este tipo de midrasîm, si bien se recogen las tradiciones existentes más importantes, no era ésta una técnica desarrollada por la interpretación halákica.

Estos resultados confieren al midrás exegético, y en general al hagádico, un papel importante en la transmisión textual, y lo confirman como una fuente imprescindible para el estudio de la misma. Y por lo tanto, sugieren una revisión de la creencia generalizada según la cual el midrás halákico es el portador natural de la información textual en detrimento del midrás hagádico, excluido de los estudios y relegado a un papel secundario por su contenido narrativo. 


\section{RESUMEN}

En este artículo se examinan todos los ejemplos de los midrašìm halákicos más antiguos (Sifré Números, Sifra Levíticos y Mẹk̂ilta’de R. Yismael) que comentan un detalle textual con un lenguaje similar al de la Masora. Los resultados de estos análisis son comparados con los obtenidos del análisis de los midrašìm exegéticos Génesis Rabbâ y Lamentaciones Rabbâ.

Dicha comparación demuestra que este tipo de comentarios son más numerosos y variados en los midrašim exegéticos. En cuanto a las noticias textuales que ambos señalan e interpretan, se pueden apreciar diferencias respecto al tratamiento y la fórmula. Todo ello confirma que en los midrasî̀m exegéticos esta era una práctica habitual de los rabinos, pero no así en los halákicos, donde parece ser un hecho puntual. Las conclusiones de este estudio resaltan la importancia de los midrašìm exegéticos, y en general los hagádicos, en los estudios sobre la historia y el desarrollo de la Masora.

Palabras Clave: Midrás, Masora, exégesis rabínica, comentarios textuales, antecedentes masoréticos, transmisión textual.

\section{SUMMARY}

In this article the author examines all the examples of the oldest halakhic midrašìm (Sifre Numbers, Sifra Leviticus and Mékîlta' de R. Ysmael) in which a textual detail is commented in the language of the Masorah. The results of these analyses are then compared with the results obtained from the analysis of the exegetical midrašim Genesis Rabbâ and Lamentations Rabbâ.

This comparison shows that this type of commentaries are more numerous and varied in the exegetical midrasîm. The comparison of the textual notes shared by both midrašim permits to appreciate the differences in the treatment and the formula. The conclusions of this study stress the significance of exegetical midrasim and the haggadic in general, in the studies about the history and development of Masorah.

KEYWORDS: Midras, Masorah, rabbinical exegesis, textual commentaries, Masoretic antecedents, textual transmission. 